University of Windsor

Scholarship at UWindsor

1976

\title{
Quantum beats in the electric-field quenching of metastable hydrogen
}

A. Van Wijngaarden

E Goh

Gordon W. F. Drake

University of Windsor

P. S. Farago

Follow this and additional works at: https://scholar.uwindsor.ca/physicspub

Part of the Physics Commons

\section{Recommended Citation}

Van Wijngaarden, A.; Goh, E; Drake, Gordon W. F.; and Farago, P. S.. (1976). Quantum beats in the electricfield quenching of metastable hydrogen. Journal of Physics B: Atomic and Molecular Physics, 9 (12),

2017-2025.

https://scholar.uwindsor.ca/physicspub/42

This Article is brought to you for free and open access by the Department of Physics at Scholarship at UWindsor. It has been accepted for inclusion in Physics Publications by an authorized administrator of Scholarship at UWindsor. For more information, please contact scholarship@uwindsor.ca. 
Relativistic corrections to spin-forbidden electric-dipole transitions

This article has been downloaded from IOPscience. Please scroll down to see the full text article.

1976 J. Phys. B: At. Mol. Phys. 9 L169

(http://iopscience.iop.org/0022-3700/9/7/001)

View the table of contents for this issue, or go to the journal homepage for more

Download details:

IP Address: 137.207.184.30

The article was downloaded on 26/04/2013 at $15: 43$

Please note that terms and conditions apply. 


\title{
LETTER TO THE EDITOR
}

\section{Relativistic corrections to spin-forbidden electric-dipole transitions $\dagger$}

\author{
G W F Drake $\ddagger$ \\ Department of Physics, University of Windsor, Windsor, Ontario, Canada N9B 3P4
}

Received 26 February 1976

\begin{abstract}
Theoretical results for spin-forbidden electric-dipole transitions have recently been questioned on the grounds that relativistic corrections to the transition operator were not included. It is shown here that these corrections are automatically included when the transition operator is expressed in the dipole length form. The above criticism of previous dipole-length calculations is therefore unfounded. The $1 \mathrm{~s} 2 \mathrm{p}^{3} \mathrm{P}_{1}-1 \mathrm{~s}^{2}{ }^{1} \mathrm{~S}_{0}$ and $1 \mathrm{~s} 2 \mathrm{p}{ }^{3} \mathrm{P}_{1}-1 \mathrm{~s} 2 \mathrm{~s}$ ${ }^{1} \mathrm{~S}_{0}$ transitions of helium are discussed as specific numerical examples.
\end{abstract}

There has been much confusion over the years concerning the correct method of evaluating transition matrix elements for spin-forbidden electric-dipole transitions. The earlier work on the subject is reviewed by Goodman and Laurenzi (1968), and it is discussed from a more general point of view by Drake (1972). The spin-forbidden transition $2^{3} \mathrm{P}_{1}-1^{1} \mathrm{~S}_{0}$ in helium-like ions is of particular interest because precise calculations with correlated variational wavefunctions are available (Drake and Dalgarno 1969), which can be compared with the measured decay rates of Sellin et al (1968) and Moore et al (1973). The purpose of this letter is to comment on some recent criticisms of the above theoretical work, particularly the corrections proposed by Laughlin (1975) to the calculations of Drake and Dalgarno.

The contributions to the transition integral can be divided into an 'indirect' part coming primarily from the spin-orbit mixing of the ${ }^{3} \mathrm{P}_{1}$ and ${ }^{1} \mathrm{P}_{1}$ states, and a 'direct' part due to relativistic spin-dependent corrections to the $p \cdot A$ form of the interaction operator. In recent papers, Luc-Koenig (1974) and Laughlin (1975) suggest that the direct part was not included in previous calculations, and Laughlin explicitly adds the direct part to the matrix elements of Drake and Dalgarno to obtain revised transition probabilities. We show here that this procedure is unfounded-in fact, both the indirect and the direct parts are automatically included, provided that the matrix element is expressed in the $\hat{\boldsymbol{e}} . \boldsymbol{r}$ (dipole length) form. As a consequence, the division into direct and indirect parts is not unique.

As shown by Drake (1972), the lowest-order interaction energy operator responsible for spin-forbidden electric-dipole transitions in the Coulomb gauge is $\S$

$$
U=U^{(1)}+U^{(3)}
$$

$\dagger$ Research supported by the National Research Council of Canada.

+ Alfred P Sloan Foundation Fellow.

$\S$ Equation (26) of Drake (1972) is printed incorrectly. The last term should be multiplied by $\frac{1}{2}$ so that it agrees with (3) overleaf. 


$$
\begin{gathered}
U^{(1)}=-\frac{e}{m c}\left(A_{1} \cdot p_{1}+A_{2} \cdot p_{2}\right) \\
U^{(3)}=-\frac{e^{2}}{4 m^{2} c^{3}} \sum_{j=1,2} \sigma_{j} \cdot \nabla V_{j} \times A_{j}-\frac{e^{3}}{4 m^{2} c^{3} r_{12}^{3}}\left(\sigma_{1} \cdot r_{12} \times A_{1}+\sigma_{2} \cdot r_{21} \times A_{2}\right)
\end{gathered}
$$

including corrections up to relative order $(\alpha Z)^{2}$. Here, $V_{j}=-Z e / r_{j}, \boldsymbol{r}_{12}=\boldsymbol{r}_{1}-\boldsymbol{r}_{2}, \boldsymbol{\sigma}$ is the Pauli spin operator and, to sufficient accuracy, $A=(2 \omega / 3 c)^{1 / 2} \hat{e}$, where $\hat{e}$ is the unit photon polarization vector and $\omega$ is its frequency. Equation (3) differs from equation (1) of Laughlin only by a term symmetric in the spin operators, which consequently does not contribute to singlet-triplet transitions.

The direct contribution comes from matrix elements of $U^{(3)}$. Both the direct and the indirect parts are included by writing the interaction energy matrix element in the form

$$
U_{\mathrm{i}-\mathrm{f}}=\left\langle\Phi_{\mathrm{f}}^{\prime}\left|U^{(1)}+U^{(3)}\right| \Phi_{\mathrm{i}}^{\prime}\right\rangle
$$

correct to terms of $\mathrm{O}\left(\alpha^{2} Z^{2}\right)$, where $\Phi^{\prime}$ is the non-relativistic wavefunction including first-order corrections for spin mixing due to the Breit interaction $B$ (Bethe and Salpeter 1957). Thus $\Phi^{\prime}$ is an eigenfunction of $H_{\backslash \mathrm{R}}+B$ up to spin-dependent terms of $\mathrm{O}\left(\alpha^{2} Z^{2}\right)$, where $H_{\mathrm{NR}}$ is the non-relativistic Hamiltonian. Using the explicit forms for $B$ and the photon vector potential $A$, it is easy to show that correct terms of $\mathrm{O}\left(x^{2} Z^{2}\right)$

$$
\begin{aligned}
\left\langle\Phi_{\mathrm{f}}^{\prime}\left|U^{(1)}+U^{(3)}\right| \Phi_{\mathrm{i}}^{\prime}\right\rangle & =i \propto(2 \omega / 3 c)^{1 / 2}\left\langle\Phi_{\mathrm{f}}^{\prime}\left|\left[\hat{e} \cdot\left(r_{1}+r_{2}\right), H_{\mathrm{NR}}+B\right]\right| \Phi_{\mathrm{i}}^{\prime}\right\rangle \\
& =\mathrm{i} \propto(2 \omega / 3 c)^{1 / 2}\left(E_{\mathrm{i}}-E_{\mathrm{f}}\right)\left\langle\Phi_{\mathrm{f}}^{\prime}\left|\hat{\boldsymbol{e}} \cdot\left(r_{1}+r_{2}\right)\right| \Phi_{\mathrm{i}}^{\prime}\right\rangle .
\end{aligned}
$$

Therefore, the contribution from $U^{(3)}$ is automatically included when the matrix element is evaluated in the dipole length form.

As a direct numerical check, the matrix elements in equation (5) were evaluated for the $1 \mathrm{~s} 2 \mathrm{p}^{3} \mathrm{P}_{1}-1 \mathrm{~s}^{2}{ }^{1} \mathrm{~S}_{0}$ and $1 \mathrm{~s} 2 \mathrm{p}{ }^{3} \mathrm{P}_{1}-1 \mathrm{~s} 2 \mathrm{~s}{ }^{1} \mathrm{~S}_{0}$ transitions of helium with the same 50-term correlated variational wavefunctions as used by Drake and Dalgarno. Except for an overall multiplying factor of $-i \alpha^{3}(2 \omega / 3 c)^{1 / 2}$, equation (5) for these transitions reduces to (in atomic units)

$$
\begin{gathered}
\alpha^{-2}\left\langle n^{1} \mathrm{~S}_{0}^{\prime}\left|\frac{\mathrm{d}}{\mathrm{d} z_{1}}+\frac{\mathrm{d}}{\mathrm{d} z_{2}}\right| 2^{3} \mathrm{P}_{1}^{\prime}\right\rangle+\frac{\sqrt{2}}{4}\left\langle n^{1} \mathrm{~S}\left|Z\left(z_{1} / r_{1}^{3}-z_{2} / r_{2}^{3}\right)+2\left(z_{1}-z_{2}\right) / r_{12}^{3}\right| 2^{3} \mathrm{P}\right\rangle \\
=\alpha^{-2}\left[E\left(2^{3} \mathrm{P}\right)-E\left(n^{1} \mathrm{~S}\right)\right]\left\langle n^{1} \mathrm{~S}_{0}^{\prime}\left|z_{1}+z_{2}\right| 2^{3} \mathrm{P}_{1}^{\prime}\right\rangle
\end{gathered}
$$

where the unprimed wavefunctions are the spin-independent eigenfunctions of $H_{\mathrm{NR}}$. The results shown in table 1 demonstrate that equation (6) is correct to within the accuracy of the calculation, whether or not there is a change in the principal quantum number. The degree to which equations (5) or (6) are satisfied is an indication of the accuracy of the wavefunctions similar to the comparison of the 'length' and 'velocity' forms for allowed transitions.

In summary, the procedure employed by Laughlin in modifying the earlier calculations of the $2^{3} \mathrm{P}_{1}-1^{1} \mathrm{~S}_{0}$ transition integral amounts to counting the contribution from $U^{(3)}$ twice. The results of Drake and Dalgarno are therefore substantially correct as they stand, even though the agreement with experiment is not quite as good as one might desire. The small correction shown in table 1 due to spin-orbit mixing between the ${ }^{1} \mathbf{S}_{0}$ and doubly excited $\mathrm{pp}^{\prime}{ }^{3} \mathbf{P}_{0}^{\mathrm{e}}$ states, which was not included by Drake and Dalgarno, becomes less important with increasing $Z$ and is negligible for the heavier helium-like ions. 
Table 1. Matrix elements for the $1 \mathrm{~s} n \mathrm{~s}^{1} \mathbf{S}_{0}-1 \mathrm{~s} 2 \mathrm{p}{ }^{3} \mathbf{P}_{1}$ transitions of heliumt.

\begin{tabular}{|c|c|c|c|}
\hline & $n=$ & 1 & 2 \\
\hline$\alpha^{-2}\left\langle n^{1} \mathrm{~S}_{0}^{\prime}\left|\frac{\mathrm{d}}{\mathrm{d} z_{1}}+\frac{\mathrm{d}}{\mathrm{d} z_{2}}\right| 2^{3} \mathrm{P}_{1}^{\prime}\right\rangle$ & & $\begin{array}{c}2 \cdot 191 \\
(2 \cdot 156)\end{array}$ & $\begin{array}{l}-0 \cdot 2102 \\
(-0 \cdot 2078)\end{array}$ \\
\hline$\frac{\sqrt{2} Z}{4}\left\langle n^{1} \mathrm{~S}\left|\frac{z_{1}}{r_{1}^{3}}-\frac{z_{2}}{r_{2}^{3}}\right| 2^{3} \mathrm{P}\right\rangle$ & & -0.177 & $0 \cdot 0122$ \\
\hline$\frac{\sqrt{2}}{2}\left\langle n^{1} S\left|\frac{z_{1}-z_{2}}{r_{12}^{3}}\right| 2^{3} \mathrm{P}\right\rangle$ & & -0.069 & 0.0119 \\
\hline Sum of above & & 1.945 & $-0 \cdot 1861$ \\
\hline $\begin{array}{l}\alpha^{-2}\left[E\left(2^{3} \mathrm{P}\right)-E\left(n^{1} \mathrm{~S}\right)\right] \\
\quad \times\left\langle n^{1} \mathrm{~S}_{0}^{\prime}\left|z_{1}+z_{2}\right| 2^{3} \mathrm{P}_{1}^{\prime}\right\rangle\end{array}$ & & $\begin{array}{l}1.949 \\
(1.962)\end{array}$ & $\begin{array}{l}-0 \cdot 1857 \\
(-0 \cdot 1859)\end{array}$ \\
\hline
\end{tabular}

The entries in the la t row di jer from the matrix elements calculated by Drake and Dalizarno $(16,69)$ since they did not include a small contribution from the mixing of the 1 sns ${ }^{1} \mathrm{~S}_{0}$ state with the doubly excited $\mathrm{pp}^{\prime}{ }^{3} \mathrm{P}_{0}^{\mathrm{c}}$ states. The values obtained without this correction are given in brackets.

\section{References}

Bethe H A and Salpeter E E 1967 Quantum Mechanics of One- and Two-Electron Atoms (Berlin: Springer-Verlag) p 181

Drake G W F 1972 Phys. Rev. A 5 1979-85

Drake G W F and Dalgarno A 1969 Astrophys. J. 157 456-62

Goodman L and Laurenzi B J 1968 Adr. Quintum Chem. 4 153-69

Laughlin C 1975 J. Phys. B: Atom. Molec. Phys 8 L400 2

Luc-Koenig E 1974 J. Phys. B: Atom. Molec. Phis. 7 1052-8

Moore C F. Braithwaite W J and Matthews D L 1973 Phrs. Lett. 44A 199200

Sellin I A, Donnally B W and Fan C Y 1968 Phys. Ret. Lett. 21 717-9 